\title{
La configuración del espacio económico en el marco de la construcción del Estado: el Oriente salvadoreño, 1840-1855
}

\author{
Clara PÉrez FABRegat \\ Universidad de Barcelona \\ claron8@hotmail.com
}

Recepción: 7 de marzo de 2012 / Revisión: 7 de mayo de 2012

Aceptación: 28 de mayo de 2012 / Publicación: Diciembre de 2012

\section{RESUMEN}

Tras la disolución del experimento federal centroamericano y el surgimiento de El Salvador como Estado independiente, la región oriental salvadoreña gozó de una posición económica privilegiada por la cercanía del puerto de La Unión en la Bahía de Fonseca, un enclave comercial que vertebró la región de San Miguel, que tradicionalmente había Estado estrechamente vinculada con el sur de Honduras y el oeste nicaragüense. El desarrollo económico de San Miguel fue el motor económico principal en la fase inicial del proceso de formación estatal de El Salvador. En este artículo se intenta dilucidar las características del proyecto que propició la configuración del espacio económico regional y al mismo tiempo, generó los recursos para constituir y modelar el Estado salvadoreño.

Palabras clave: La Unión, San Miguel, El Salvador, formación estatal, historia regional, fiscalidad, siglo XIX.

\section{The Shaping of the Economic Area in the State-Building Framework: Eastern EI Salvador, 1840-1855}

\begin{abstract}
From the dissolution of the Central American federation until the middle of $19^{\text {th }}$ century, the Eastern region of El Salvador enjoyed a privileged economic position because of its proximity of the port of $\mathrm{La}$ Union, on the Bay of Fonseca, a commercial enclave that supported the entire region of San Miguel, which was traditionally interrelated with Southern Honduras and Western Nicaragua. The economic development of San Miguel was the main economic driving force in the initial period of state-formation in El Salvador. This article attempts to explain the project that facilitated the configuration of the regional economy and, at the same time, generated the resources that gave shape to a new political entity.
\end{abstract}

Key words: La Unión, San Miguel, El Salvador, State Formation, Regional History, Taxation, 19th Century.

Sumario: 1. Introducción. 2. Un enlace con el mercado mundial: los puertos de El Salvador entre 18471855. 3. Apuntes sobre fiscalidad: finanzas y comercio en el oriente salvadoreño. 4. A modo de conclusión. 5. Referencias bibliográficas. 


\section{INTRODUCCIÓN}

La antigua provincia de San Salvador, parte del Reino de Guatemala, contenía una entidad socioeconómica particular al este del río Lempa ${ }^{1}$. El espacio oriental salvadoreño vertebrado por la ciudad de San Miguel y más tarde por el puerto de La Unión se puede analizar como una región histórica vinculada al sur hondureño y al oeste nicaragüense por la estructura productiva del añil durante un período de tiempo concreto; desde la fase tardío-colonial hasta su fragmentación política tras la guerra que enfrentó a Guatemala y El Salvador en 1863. Se entiende por Oriente salvadoreño aquel espacio que limita al Norte con Honduras, al Sur con el océano Pacífico, al Este con la Bahía de Conchagua o Fonseca y al Oeste con el río Lempa (Mapa 1). El río fue una frontera natural que aisló parcialmente la zona oriental del resto del país dando lugar a una realidad socioeconómica más vinculada a los centros de Comayagua y León ${ }^{2}$.

A mediados del siglo XVIII, el añil, demandado en las zonas de producción textil europeas, incentivó el desarrollo de la actividad ganadera en Nicaragua y Honduras por la necesidad de la carne para alimentar a los trabajadores de los obrajes y el cuero para fabricar zurrones donde almacenar el añil (Acuña, 1982). Ya en el siglo XIX, la progresiva liberalización económica tras la independencia permitió la descentralización del comercio. La activación del puerto de La Unión en 1824, entre otros, dinamizó el movimiento por el Pacífico y en consecuencia se convirtió en un eje vertebrador de la economía oriental ya que sirvió para dar salida a los productos de toda la zona oriental salvadoreña además del Sur de Honduras, incluyendo Comayagua y Tegucigalpa ${ }^{3}$.

A pesar de los altibajos en la demanda, el añil fue el motor que inyectó recursos fiscales al Estado salvadoreño hasta bien entrado el siglo XIX. Producido en las zonas bajas costeras del Pacífico y exportado a Europa, la circulación del tinte siguió prácticamente el mismo del sistema comercial colonial. En la segunda mitad del siglo XIX, el aumento del precio del café, la difícil colocación del añil en los mercados europeos y la llegada de los colorantes químicos hicieron que el café desbancara al tinte como principal producto de exportación. Esto impulsó el cambio del tejido socioeconómico salvadoreño por la necesidad de mano de obra, tierras, capital y transporte ${ }^{4}$.

\footnotetext{
1 Este trabajo se enmarca en el proyecto de tesis doctoral, San Miguel y el oriente salvadoreño. ¿Una Región dentro del Estado? Una mirada al proceso de la construcción del Estado de El Salvador, 1840-1890, dirigido por Pilar García Jordán y Antonio Acosta inscrito en el programa de "Sociedad y Cultura" de la Universidad de Barcelona.

2 Existe una escueta bibliografía que toma como elemento de análisis el Oriente salvadoreño o el entorno de la ciudad de San Miguel: Chamberlain, 1947; Lauria, 2011; Avendaño, 2006; CAmpos, 2006.

3 Solórzano, 1993, pp. 15, 34.

4 Menjívar, 1980 , p. 89.
} 
Mapa 1. Límites fronterizos de El Salvador en 1840

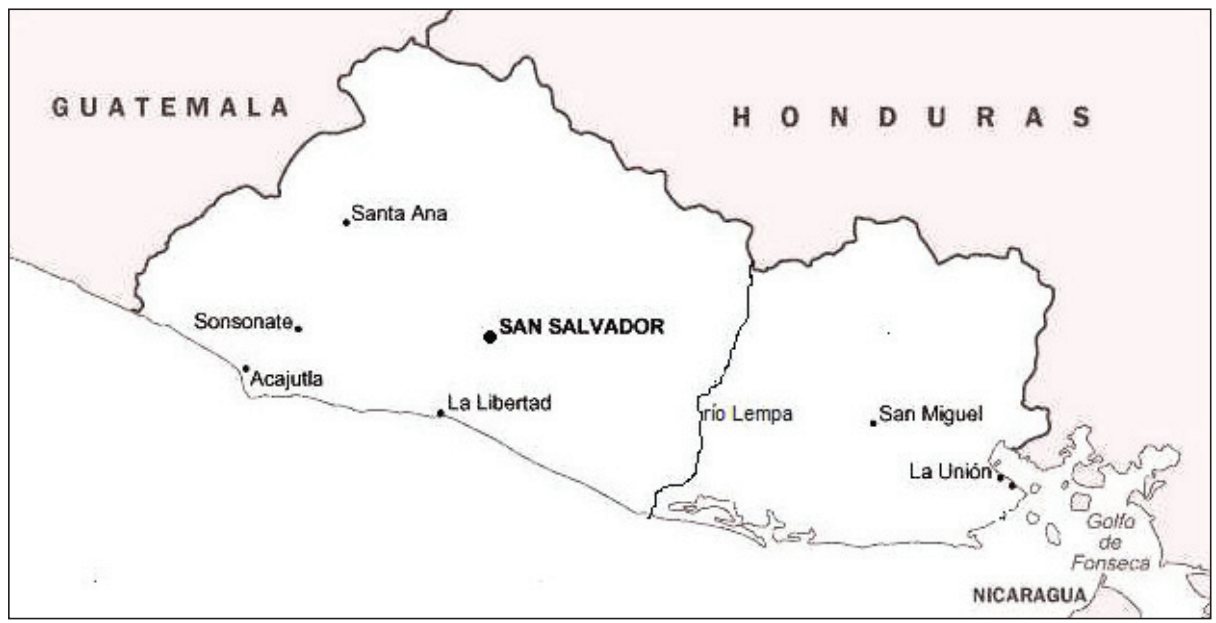

Fuente: elaboración propia.

El éxito de la colocación del café salvadoreño en el mercado mundial y su correspondiente generación de recursos aceleró la progresiva consolidación del Estado liberal a partir de 1870 aproximadamente. La modelación de éste corrió a cargo de unos actores sociales vinculados al beneficiado y la exportación del café 5 .

La implementación de este proyecto político-económico se hizo a partir de las reformas liberales. En el caso salvadoreño se basaron en la privatización de las tierras comunales y ejidales a pesar de que en el plano centroamericano, este reordenamiento pasó por desvincular a la Iglesia del poder político y económico. Pero la Iglesia salvadoreña dependió hasta 1842 de la Archidiócesis de Guatemala, donde quedaron concentradas todas las grandes propiedades. Con la limitación del poder corporativo se buscó un cambio institucional para ordenar recursos, eliminar dificultades legales y consuetudinarias para el desarrollo de una economía de exportación que permitiera la inserción de El Salvador en la economía mundial ${ }^{6}$.

El objetivo de este artículo es reflexionar sobre el proceso de configuración del espacio económico oriental de El Salvador y su influjo en el desarrollo económico del resto del país a partir del análisis de varios aspectos fiscales y comerciales del puerto de La Unión y la ciudad de San Miguel. El marco temporal elegido de 1840 a 1855, previo a la consolidación del café como principal producto de exportación, corresponde a los primeros años de la República de El Salvador tras la disolución de la Federación Centroamericana. El hilo argumental de este texto se enmarca en la noción de la transición gradual hacia la formación de un Estado moderno sin rupturas reales como explicaron Gudmundson y Lindo al hacer una revisión del periodo del pre-liberalismo. Concluyeron que la idea de la larga espera que hace referencia

5 Lindo-Fuentes, 2002; Lauria, 2003; Acosta, 2006, 2007, 2008; Williams, 1994; Menjívar, 1980; ColinDREs, 1977; Portillo, 2004; Browning, 1974.

6 López Bernal, 2008; Taracena, 1993, p. 168. 
al periodo entre la independencia y las reformas liberales no fue sólo un impasse de anarquía sino que ya se estaba caminando en la senda de la construcción estatal y las reformas liberales fueron la formalización de este proceso y no una ruptura radical de la dinámica socioeconómica del país.

Se plantea que la región oriental salvadoreña tuvo una importante función en el desarrollo económico del país y en el proceso de formación estatal en las primeras décadas de vida independiente. Se propone un enfoque, poco aplicado en el campo de la formación del Estado, basado en el análisis de la participación regional en el proceso de configuración de las instituciones estatales concretamente mediante el trasvase de recursos financieros de las regiones al gobierno central. La perspectiva tradicional ha tendido a un enfoque centralista y, en consecuencia, son pocos los investigadores que se han acercado al ámbito local o regional para explicar el proceso y el impacto en la formación estatal desde el punto de vista de la privatización de la tierra, el vínculo con el poder central en el siglo XIX, o las haciendas locales en el sistema fiscal ${ }^{7}$. Por todo ello, consideramos esencial que se establezca un diálogo entre las regiones y el Estado central en su proceso formativo. El reducido tamaño del país no es motivo para caer en la tentación de pensar la historia salvadoreña desde la homogeneidad política y económica o la inexistencia de diferencias territoriales.

La investigación se ha centrado en el análisis del desarrollo comercial del puerto de La Unión y el impacto de la fiscalidad aduanal y de la Administración Departamental de Rentas de San Miguel, la oficina de la hacienda pública más importante de la región. Se han buscado indicadores para cuantificar procesos que de otra forma no serían visibles como los niveles del movimiento marítimo. Los porcentajes presentados son aproximativos a la realidad económica y a la vinculación de la región de San Miguel con la estructura estatal central. Probablemente las investigaciones futuras modificaran los datos y porcentajes presentados porque las fuentes no proporcionan series continuadas de información.

Las fuentes utilizadas se encuentran en el Diario Oficial y consisten en registros de aduanas e informes fiscales y estados de cuenta aduanales y de la administración departamental de rentas de San Miguel. Parte de las fuentes tiene un carácter comercial por eso conviene señalar lo que apuntó Schoonover sobre este tipo de fuentes ${ }^{8}$. La documentación emitida en Centroamérica carece de fiabilidad y precisión porque la mayoría de agentes implicados en la transacción comercial -importadores, exportadores y empleados públicos- tuvieron motivos para manipular la información por lo que hay que valorar los datos con sumo cuidado. Los importadores extranjeros tendían a desvalorizar sus productos para lograr una reducción de los impuestos a pagar. Lo mismo hacían los exportadores del país, minimizando el valor o el peso de lo que embarcaban. Los agentes aduanales podían ajustar los datos por dinero bajo mano o para cuadrar las cuentas a final del mes. Schoonover duda de la capacidad del método de los encargados de los registros aduanales; lo que se ve reflejado en algunas ocasiones con errores de sumas totales o repeticiones de data con variaciones en la documentación analizada. A pesar de que se ha buscado utilizar específicamente

\footnotetext{
7 LAURIA, 2003; LóPEZ Bernal, 2007; Acosta, 2007a, 2007b.

8 SChOnOover, 1978, pp. 157-169, 158; sobre la calidad de los registros comerciales en Centroamérica también vease GUDMUNDSON - LiNDO, 1995, pp.59-60.
} 
datos cuantitativos cabe mencionar que existe una amplia literatura de viajeros que durante el siglo XIX viajaron por los países centroamericanos y que contiene una valiosa información cualitativa del periodo de estudio9.

El texto se compone de dos partes. La primera sección se centra en el análisis de la dinámica comercial del puerto de La Unión a partir del movimiento marítimo y los niveles de importación y exportación. En la segunda parte se revisa la fiscalidad de la aduana de La Unión y la hacienda departamental de San Miguel, resaltando los vínculos con el gobierno central.

\section{UN ENLACE CON EL MERCADO MUNDIAL: LOS PUERTOS DE EL SALVADOR ENTRE 1847-1855}

A partir de los registros de movimiento marítimo realizados por los empleados de aduanas, donde anotaban la entrada y salida de los buques publicado en el Diario Oficial, se ha revisado del grado de vinculación del desarrollo económico del país con el mercado exterior a través del comercio de importación y exportación. Se hace una descripción de las dinámicas del movimiento marítimo y se ponderan cuáles fueron las áreas y periodos del año de mayor concurrencia. Además se describen los niveles de exportación e importación de La Unión, teniendo en cuenta los principales artículos que motivaron el tráfico, así como el flujo comercial de los otros enclaves portuarios.

Se trata de una rica documentación en la que la mayoría de las veces se adjuntaba una breve reseña sobre el origen o destino del navío, tonelaje del buque, tipología de productos que transportaba, además de la tripulación, nombre del capitán y consignatario de las mercancías. No obstante, sólo se ha podido analizar el movimiento marítimo de 1847 a 1855 porque no se han encontrado ejemplares de la gaceta del gobierno u otros registros anteriores.

Hasta el momento pocos autores han mencionado el desarrollo económico de los puertos salvadoreños ${ }^{10}$. Lindo Fuentes recordó que la fiebre del oro en California y la construcción del ferrocarril en Panamá significaron un antes y un después en el desarrollo de la economía del país ${ }^{11}$. Sin embargo, aporta escasa información sobre el periodo de estudio.

\subsection{Las dinámicas internas del movimiento marítimo}

El examen de las entradas y salidas de los buques permite constatar que La Unión era un punto clave en la costa salvadoreña. El total de navíos llegados a puertos salvadoreños en el período 1847-1855 fue de 555. En esos nueve años, 321 se re-

\footnotetext{
9 Sobre la realidad de las primeras décadas independientes vista por viajeros europeos y norteamericanos véase por ejemplo Squier, 1856; Dunlop, 1847; TeMPSKY, 1858; Belot, 1865.

10 Para otros análisis socioeconómicos regionales con el puerto como eje central véase PAYNE, 2006; Campos, 2010.

11 Lindo, 2002, pp. 164-165.
} 
gistraron en La Unión, 208 en Acajutla, 24 en La Libertad y se inscribieron dos en el puerto de La Concordia. El peso de La Unión en el conjunto de los puertos es notable, puesto que significó un 57,84\% del total de embarques, quedando muy por debajo el puerto de Acajutla con un $37,75 \%$ del total ${ }^{12}$. El puerto de La Unión junto con el del Realejo en Nicaragua, fueron los mejores puertos del Pacífico entre San Francisco y Guayaquil, porque ofrecían un fondeadero seguro durante todo el año, al estar resguardados de vientos y mareas en la bahía de Conchagua ${ }^{13}$.

La comparación de entradas por años deja ver a simple vista el efecto de las convulsiones políticas del periodo. Entre los años 1848 y 1850 , la escasez de entradas fue el resultado de los bloqueos británicos a los puertos del Estado. Esta medida coercitiva del gobierno inglés fue una forma muy expedita de obligar a los gobiernos a responder a sus acreedores británicos ${ }^{14}$.

En ese contexto político, el año 1850 sólo se registraron seis buques a lo largo y ancho de toda la costa salvadoreña. La recuperación llegó el año 1851 y el pico en 1852 con la entrada de 51 y 70 buques en La Unión respectivamente, y 28 y 49 en Acajutla. Sin embargo los datos hay que analizarlos con cautela porque, por ejemplo, el año 1848 no se registró ningún buque en el puerto de Acajutla pero lo más probable es que aquel año esa información no se publicara en la Gaceta ${ }^{15}$. En el cotejo de los datos por meses (Cuadro 1) queda plasmada la influencia de las ferias de San Miguel en el movimiento marítimo porque los momentos de mayor concurrencia fueron los meses de feria, sobretodo la de noviembre, momento que concentra el 19,94\% del movimiento anual ${ }^{16}$.

Se constata entonces que La Unión fue el puerto salvadoreño que recibió un mayor número de buques en esos años y que éstos llegaron principalmente en los meses de las ferias de San Miguel. Es importante complementar esta información y contrastarla porque la entrada de buques es un indicador del flujo comercial pero no es determinante porque podían entrar o salir buques en lastre o vacíos, sólo para hacer aguada. Conviene indagar ahora cuál fue el impacto de ese movimiento.

12 Movimiento Marítimo en la Gaceta del gobierno del Salvador en la América Central [en adelante Gaceta... 1847-1855].

13 NAYLOR, 1988, p. 86.

14 La vida política salvadoreña en la primera mitad del siglo XIX contó con la participación del cónsul inglés para Centroamérica, Frederick Chatfield por la fuerte presencia británica en el istmo. Los comerciantes británicos asentados en la región facilitaron créditos a gobiernos y particulares pero la compleja coyuntura económica dificultaba la devolución de las deudas, lo cual generaba a menudo conflictos diplomáticos. Sobre la presencia británica en Centroamérica y la conflictiva figura del cónsul véase RoDRíGUEZ, 1970.

15 Movimiento Marítimo, en la Gaceta... 1847-1855.

16 Hubo una feria en el mes de mayo que, en menor medida, también concentró parte del movimiento en las costas orientales. 
Cuadro 1. Relación mensual de entradas de buques al puerto de La Unión

\begin{tabular}{|l|c|c|c|c|c|c|c|c|c|c|c|}
\hline & $\mathbf{1 8 4 7}$ & $\mathbf{1 8 4 8}$ & $\mathbf{1 8 4 9}$ & $\mathbf{1 8 5 0}$ & $\mathbf{1 8 5 1}$ & $\mathbf{1 8 5 2}$ & $\mathbf{1 8 5 3}$ & $\mathbf{1 8 5 4}$ & $\mathbf{1 8 5 5}$ & TOTAL & $\mathbf{\%}$ \\
\hline enero & & & & & & 8 & 3 & 7 & 5 & 23 & $7,17 \%$ \\
\hline febrero & 5 & & 4 & & & 5 & 2 & 2 & 5 & 23 & $7,17 \%$ \\
\hline marzo & & & 5 & & & 6 & 3 & 6 & 6 & 26 & $8,10 \%$ \\
\hline abril & & 2 & 3 & & 5 & 6 & 6 & 2 & 7 & 31 & $9,66 \%$ \\
\hline mayo & & 3 & & 4 & 9 & 6 & 4 & 2 & 4 & 32 & $9,97 \%$ \\
\hline junio & & & 1 & & & 4 & 3 & 2 & 4 & 14 & $4,36 \%$ \\
\hline julio & & 4 & 1 & & 1 & 6 & 2 & 2 & 1 & 17 & $5,30 \%$ \\
\hline agosto & & & 2 & & 2 & 1 & 1 & & 2 & 8 & $2,49 \%$ \\
\hline septiembre & & & & & 2 & 5 & 5 & 1 & 2 & 15 & $4,67 \%$ \\
\hline octubre & & & 2 & & 7 & 8 & 9 & 3 & 5 & 34 & $10,59 \%$ \\
\hline noviembre & 6 & 8 & & & 18 & 8 & 5 & 12 & 7 & 64 & $19,94 \%$ \\
\hline diciembre & 6 & & 4 & & 7 & 7 & 3 & 5 & 2 & 34 & $10,59 \%$ \\
\hline Total anual & $\mathbf{1 7}$ & $\mathbf{1 7}$ & $\mathbf{2 2}$ & $\mathbf{4}$ & $\mathbf{5 1}$ & $\mathbf{7 0}$ & $\mathbf{4 6}$ & $\mathbf{4 4}$ & $\mathbf{5 0}$ & $\mathbf{3 2 1}$ & $100 \%$ \\
\hline
\end{tabular}

Fuente: elaboración propia a partir de "Movimiento Marítimo” en la Gaceta... 1847-1855.

\subsection{El efecto del comercio exterior en el estado salvadoreño}

En la primera mitad del siglo XIX, en el marco de la realización del capital a escala mundial impulsado por la política del libre cambio ${ }^{17}$, el contacto comercial de El Salvador con el exterior fue modesto porque el intercambio se realizaba con productos que podían pagar altos costos de transporte y la cantidad de personas que podía pagar estos costos fue reducido. Quesada recuerda que en este periodo la inserción de las economías centroamericanas en el mercado mundial fue posible con la revolución de los transportes que permitieron movilizar grandes cantidades de mercancías.

La documentación sobre el comercio externo sólo aporta datos de volumen y valor de los productos exportados por el Oriente del país; el único registro detallado de las exportaciones por el Occidente corresponde a 1855. Los índices generales del valor de las exportaciones anuales presentan 1852 como el año de bonanza económica lo que coincide con los niveles más altos de movimiento marítimo (Cuadro 1). Si bien los valores de las exportaciones eran considerables, esto no suponía una entrada equivalente de liquidez a la arcas del Estado, puesto que parte de este monto se cubría con bonos y vales del Estado. Las cantidades se expresaban en pesos, unidad más o menos equivalente al dólar de los Estados Unidos y que coexistió por mucho tiempo con monedas de otros lugares ${ }^{18}$.

17 Quesada, 1985, p. 77.

18 Gudmundson-Lindo, 1995, p. 61. 
En esos años, el principal producto de exportación fue el añil. Su alto precio por poco volumen y la buena conservación durante el transporte facilitaron esta dinámica. No obstante, la producción sufrió un fuerte declive por la inestabilidad política post-federal que obligó a transferir recursos humanos y materiales para sostener un estado de guerra casi permanente ${ }^{19}$. En los cinco años alternos analizados (1849, $1850,1852,1853,1855)$ el añil ocupó el primer lugar con un $86 \%$ del total, seguido de los cueros de res y venado en un 10\% que servían para la elaboración de los zurrones para empaquetar el tinte. En menor medida, se exportó tabaco y tejidos de algodón ${ }^{20}$. En cantidades muy pequeñas, también se exportaron maderas, aguardiente, petates, cigarros y puros, brozas minerales, azúcar, algunas especias como pimienta y vainilla, gallinas, cerdos, reses y bálsamo, entre otros. La comparación de los datos comerciales de 1855 de todos los puertos muestra que los índices de exportación del puerto de La Unión fueron los más altos, lo que concuerda con la dinámica de movimiento marítimo del mismo ${ }^{21}$.

El flujo comercial del puerto de La Unión encaja en la tendencia centroamericana de exportaciones hacia Inglaterra. Entre 1851 y 1855, en el total centroamericano, $4 \%$ eran maderas, $89 \%$ tintes y un $7 \%$ bajo el concepto de otros, que incluía metales, algodón bruto, cebo, conchas-perla y de tortuga ${ }^{22}$. En el presente análisis sólo se ha contabilizado el comercio exterior por vía marítima porque los registros en los puestos fronterizos terrestres son casi inexistentes.

En el caso de las importaciones la información es más escueta. Sólo se detallaba la procedencia de los productos con lo cual el dato no puede ser concluyente si tenemos en cuenta que los buques solían hacer largas rutas con paradas intermedias en varios puertos importantes como El Callao o Valparaíso.

Las importaciones se formaron de un $86 \%$ de textiles y manufacturas, un $4 \%$ de artículos para el consumidor y un $8 \%$ de bienes de capital ${ }^{23}$. La mayoría fueron manufacturas textiles de algodón, ya fuera ordinario o estampado, consumido por los sectores populares e importados en grandes cantidades. Los artículos de lana también eran muy preciados. Además, Inglaterra abastecía el ámbito de la ferretería y artículos forjados de hierro, acero, latón, cobre, plomo y hojalata. Existían productos más especializados como agujas o utensilios de carnicería, platos, espadas o instrumentos de carpintería, entre otros ${ }^{24}$. La entrada de grandes cantidades de artículos y artefactos diversos se contabilizaron a menudo como "bultos de efectos o mercancías extranjeras".

En la primera mitad del siglo XIX el origen y destino principal de los productos fue Gran Bretaña que ocupó el espacio dejado por la Monarquía hispánica cuando el gobierno federal centroamericano abrió sus puertos al comercio exterior. Los intercambios legales siguieron los canales establecidos por el antiguo tráfico ilegal de los

19 Lindo, 1993, p. 56 y ss.

20 Gaceta..., 26-X-1849, 22-XI-1850, 4-II-1853, 28-X-1853, 27-XII-1855.

21 El total de exportaciones según la vía de salida: La Unión 53\%; Fronteras Guatemala-Honduras 27\%; La Libertad, 15\%; Acajutla 5\% en Gaceta..., 27-XII-1855.

22 QuesADA, 1985, p. 85.

23 QuesADA, 1985, p. 89.

24 NAYLOR, 1988, p. 103. 
ingleses, asentados en la costa Atlántica, por el Reino de Guatemala ${ }^{25}$. La delicada situación económica del istmo, fue aliviada por la expansión comercial inglesa que buscaba asegurarse nuevos mercados y materias primas para su industria. Por eso el movimiento marítimo del puerto de La Unión se tradujo en un importante flujo comercial basado fundamentalmente en la exportación del añil y la importación de tejidos europeos. La estructura de mercado generada por el gran volumen de transacciones tuvo un impacto económico considerable en la región oriental.

\subsection{La operatividad de las transacciones comerciales}

En las décadas centrales del siglo, las perspectivas comerciales de El Salvador disminuyeron a raíz de las guerras civiles tras el colapso de la Federación. La falta de una salida al Atlántico significó un muro arancelario para llegar hasta allí o negociar con las casas beliceñas. Por eso se comenzó a negociar con compañías inglesas que tenían casas filiales en el sur como Naylors \& Boardman de Valparaíso, Todd, Naylors \& Co de Liverpool, Myers \& Bland de Valparaíso y Lima y Reid \& Swayne de Lima ${ }^{26}$.

Las ventas se hacían a través de una larga cadena de agentes intermediarios. Las casas comerciales inglesas, reacias a establecer filiales en cualquiera de los cinco Estados centroamericanos, prefirieron contratar a comerciantes residentes en el istmo a través de las filiales y casas de comisión que existían en Belice, Jamaica, Chile y Perú $^{27}$. Los registros de movimiento marítimo permiten deducir quiénes fueron los principales agentes comerciales en la región. Parece que una praxis común fue que los propios capitanes de los buques ejercieran de consignatarios de las mercancías y encargados de venderlas o intercambiarlas en su destino. Este fue el caso de Antonio Raymundi, Bartolome Vialo, Clemente Dacoingh, Domingo Viñas, Henry Cole, Jaime Busclay, Juan Contreras o Juan Santo Antonio entre otros. Pero además destacan personajes, dignos de estudios posteriores, como Joaquín Mathé, conocido por ser delegado de las casas beliceñas que fue consignatario de mercancías ocho veces en los años registrados. Florentín Souza fue otro comerciante vinculado con las filiales del Perú que, además, llegó a ser vicecónsul del Perú. Mariano Fernández, Pedro Alvarado y Gil Chacón fueron consignatarios nueve, once y siete veces respectivamente de productos que llegaron en buques de bandera costarricense. La sociedad de Ruiz y Romagosa de Sonsonate ejerció de agente comercial numerosas veces: nueve como sociedad y cuatro más a título personal de los socios.

Conviene detenerse un momento sobre dos personajes que, en nuestra opinión, son bastante interesantes porque en ellos se materializa la acumulación de poder económico pues la mayoría de veces la misma persona ejercía de importador, exportador, prestamista, distribuidor y político. Nos referimos a Santiago González y Yanuario Blanco; el primero fue el único propietario de buque que aparece en los registros. Compró el "Trinidad", que tuvo una importante trayectoria de cabotaje con un total de 23 entradas registradas a los puertos salvadoreños. En la mayoría de los viajes

25 NAYLOR, 1960, p. 364, pp. 364 y 366.

26 NAYLOR, 1988, p. 115.

27 Ibídem, p. 104. 
apareció como consignatario de las mercancías que se transportaron. El segundo fue diputado, comerciante asentado en San Salvador y fungió como agente del comercio británico ${ }^{28}$.

Estos comerciantes suministraban los productos en las tres ferias de San Miguel. Usualmente, antes de cada feria se dejaba a los comerciantes las mercancías equivalentes en valor al añil exportado. Este sistema se fue sustituyendo por la embarcación directa de los productos por la vía del Cabo de Hornos. Tras la ruptura de la Federación, la importancia de las ferias fue menguando porque el añil tuvo una tendencia descendente y porque los productos adquiridos que tenían que trasladarse a los otros Estados estaban sujetos a pagos adicionales ${ }^{29}$. Sin embargo, en estos encuentros no sólo hubo espacio para efectuar el comercio exterior, sino también intrarregional y local.

El mercado estuvo dominado por aquellos grandes comerciantes que controlaron el crédito. Para comprender esta dinámica hay que retroceder un poco. En Centroamérica la tierra fue el factor de producción más abundante $\mathrm{y}$, por ende, no fue el principal elemento de poder y riqueza. Lo más escaso fue la capacidad empresarial, el crédito y la mano de obra ${ }^{30}$. Gozaron de poder quienes controlaron el crédito y los mecanismos de comercialización, como fue el caso de los comerciantes guatemaltecos en la fase tardíocolonial. La modalidad crediticia más común fue la "habilitación", un desembolso en dinero o mercancías a devolver al año siguiente con la cosecha de añil. Habitualmente, aunque el interés fuera de un 5\%, el acreedor obtenía más beneficios porque no sólo tenía la capacidad de negociar los precios del añil por adelantado, sino también valuar las mercancías que proporcionaba ${ }^{31}$.

\section{APUNTES SOBRE FISCALIDAD: FINANZAS Y COMERCIO EN EL ORIENTE SALVADOREÑO}

La dinámica comercial del Oriente salvadoreño quedó dibujada en la fiscalidad estatal. El impacto económico del comercio puede leerse a partir de las cuentas aduanales y departamentales de la hacienda pública.

Para el caso de la Aduana, las cuentas de la Tesorería general muestran la importancia de las fronteras marítimas como punto de recaudación fiscal en comparación con las terrestres u otro tipo de administraciones de rentas públicas, mientras que por los estados de cuenta remitidos por el encargado aduanero se puede precisar la cantidad, la calidad y el uso de los fondos aduanales correspondientes al puerto de La Unión. La fiscalidad de San Miguel y su impacto en la distribución de gastos del Estado salvadoreño puede trabajarse a partir de los informes fiscales del administrador de rentas del departamento.

\footnotetext{
28 Movimiento marítimo, en Gaceta... 1847-1855.

29 NAYLOR, 1988, p. 123.

30 Lindo, 1993, pp. 141-143.

31 Ibídem, p. 148; AcUÑA, 1982.
} 


\subsection{Las administraciones de rentas marítimas en la hacienda pública salvadoreña}

En los escasos balances fiscales publicados por la Tesorería General, las cuentas aduanales quedaban en un segundo plano por detrás del ramo del aguardiente. No obstante, al tomar en consideración el contexto político-económico, crece la sospecha que estos datos presentaron una realidad parcializada puesto que no muestran la lógica fiscal de un Estado que empezaba a vincularse al comercio exterior. La transición económica que significó la independencia supuso una dependencia de los impuestos del comercio, porque gravar otras actividades era difícil de administrar y fácil de evadir. A pesar de la moda decimonónica impulsada por Inglaterra del librecambismo, los nuevos Estados se vieron obligados a establecer muros "protectores" para asegurarse una fuente de ingresos ${ }^{32}$.

La ausencia de este rubro en las cuentas generales de la hacienda pública quizás deba interpretarse como fruto del escaso desarrollo estatal y no como resultado de la poca importancia de los fondos de aduanas. La débil estructura estatal impidió el control del territorio y los puntos de recaudación fiscal así como homogeneizar correctamente todas las cuentas. Según la ley, la estructura primigenia de la hacienda pública salvadoreña estuvo centralizada por la Tesorería General y la Contaduría Mayor. De ella se derivaron las diversas administraciones de rentas departamentales y otras oficinas de recaudación fiscal especializadas como las administraciones de aguardiente o las aduanales que tenían que pasar cuentas a las oficinas centrales aunque en la práctica se llevaron cuentas separadas para las rentas aduanales.

Cuadro 2. Porcentaje de los fondos aduanales y del aguardiente en el total de la hacienda pública, 1847-1855

\begin{tabular}{|c|c|c|c|c|c|}
\hline Año & $\begin{array}{c}\text { Ingresos Fiscales } \\
\text { Totales }\end{array}$ & $\begin{array}{c}\text { Ingresos } \\
\text { aduanales* }\end{array}$ & $\begin{array}{c}\text { \% respecto } \\
\text { ingresos totales }\end{array}$ & $\begin{array}{c}\text { Ingresos } \\
\text { aguardiente }\end{array}$ & $\begin{array}{c}\% \text { respecto } \\
\text { ingresos totales }\end{array}$ \\
\hline 1847 & 172.661 & & & 65.231 & $37,78 \%$ \\
\hline 1848 & 64.615 & & & 30.014 & $46,45 \%$ \\
\hline 1849 & 387.372 & 120.812 & $31,19 \%$ & 185.426 & $47,87 \%$ \\
\hline 1850 & 325.610 & 112.610 & $34,58 \%$ & 147.380 & $45,26 \%$ \\
\hline 1851 & 327.177 & 122.569 & $37,46 \%$ & 115.692 & $35,36 \%$ \\
\hline 1852 & 410.351 & 238.135 & $58,03 \%$ & 110.592 & $26,95 \%$ \\
\hline 1853 & 404.415 & 173.962 & $43,02 \%$ & 176.194 & $43,57 \%$ \\
\hline 1854 & 498.192 & 214.336 & $43,02 \%$ & 227.500 & $45,66 \%$ \\
\hline 1855 & 446.824 & 182.551 & $40,86 \%$ & 193.471 & $43,30 \%$ \\
\hline
\end{tabular}

Fuente: elaboración propia a partir de «Resumen comparativo de las rentas marítimas y terrestres de la República del Salvador», Gaceta..., San Salvador, 27 mayo 1857.

* Los ingresos aduanales incluyen alcabala marítima, extracción de añil, impuesto aguardiente extranjero, despacho de buques, bodegaje, tonelaje, aguada cobrada en Acajutla, papel sellado y peaje para caminos cobrados en todos los puertos de la República.

32 Bulmer-Thomas, 2003, p. 47. 
La relación de los ingresos aduanales y los del ramo del aguardiente respecto del total de ingresos fiscales del Estado (Cuadro 2), muestra que ambos conceptos compartieron protagonismo. Sin embargo, los fondos aduanales fueron incrementándose progresivamente llegando en 1852 a significar un 58,03\% del total de ingresos fiscales, mientras que el aguardiente significó un $26,95 \%$ del total. En los años siguientes ambos montos quedaron equiparados en torno al $40-45 \%$ respecto del total ${ }^{33}$. Cabe ahora preguntarse cuál fue el rendimiento fiscal de la Aduana de La Unión, o en otras palabras, qué significó éste para la economía salvadoreña.

\subsection{La aduana del puerto de La Unión en el engranaje fiscal salvadoreño}

Las aduanas marítimas fueron unos de los pocos espacios en los que el Estado tuvo la capacidad operativa de hacerse presente mediante una guarnición militar y un cuadro de empleados civiles. En el periodo estudiado, fueron las únicas administraciones de rentas cuyos detalles de contabilidad se hicieron públicos, algo nada extraño por la importancia estratégica que tenían para el Estado. Aun así, los extractos de cuentas aduanales presentan inconvenientes porque algunos no seguían un orden uniforme y cronológico porque terminaban y empezaban según el tiempo de servicio del empleado correspondiente.

\subsubsection{El origen de los ingresos}

El impuesto que generó más entradas, en los años de muestra, fue la alcabala marítima con más del $80 \%$ del total de ingresos de La Unión (Cuadro 3). Fue un arbitrio de origen colonial que gravó cualquier transacción comercial y varió en función del origen y el tipo de producto importado. La grave situación fiscal en la que se encontraron los nuevos gobiernos tras la independencia obligó a preocuparse más por amoldar las políticas fiscales a las coyunturas económicas, que a incentivar el comercio $^{34}$. Hubo constantes variaciones en los decretos sobre qué, cuándo y cuánto gravar los productos que entraban al país. Los primeros gravámenes a la importación fueron parte del legado federal y rondaban el 4 y $6 \%$ ad valorem, exceptuando los productos de algodón que pagaron un 10\%, salvo aquellos que venían de otros países latinoamericanos. Un gesto de solidaridad entre países que fue aprovechado por las casas comerciales europeas en Chile y Perú. Los artículos importados directamente por nacionales pagaban solo un $1 \%$ ad valorem. Al darse cuenta de las posibilidades de ingresos a partir de estas cargas fiscales, las políticas económicas aplicadas tendieron a aumentarlas sin pensar en las consecuencias.

\footnotetext{
33 Walter y Ramírez utilizaron la misma fuente para hablar sobre la fiscalidad previa a las reformas liberales, fijándose sólo en los ingresos aduanales percibidos por la importación y la exportación, sin contar otros tipos de ingresos que hubo en aduanas, WALTER - RAMírez, 2008, p. 134.

34 NAYLOR, 1988, p. 56.
} 
Cuadro 3. Tipo de impuestos y cantidades recaudadas en la Aduana de La Unión, 1847, $1850-1853$

\begin{tabular}{|l|r|r|r|r|r|r|}
\hline Impuestos & \multicolumn{1}{|c|}{$\mathbf{1 8 4 7}$} & \multicolumn{1}{c|}{$\mathbf{1 8 5 0}$} & \multicolumn{1}{c|}{$\mathbf{1 8 5 1}$} & \multicolumn{1}{c|}{$\mathbf{1 8 5 3}$} & \multicolumn{1}{c|}{ TOTAL } & \multicolumn{1}{c|}{$\%$} \\
\hline alcabala marítima & $\$ 6.486,13$ & $\$ 46.139,41$ & $\$ 30.496,64$ & $\$ 68.697,36$ & $\$ 151.819,54$ & $82,03 \%$ \\
\hline $10 \%$ del café & $\$ 86,37$ & $\$ 122,39$ & $\$ 75,26$ & $\$ 50,80$ & $\$ 334,82$ & $0,18 \%$ \\
\hline bodegaje & $\$ 4.030,03$ & $\$ 5.828,39$ & $\$ 3.595,05$ & $\$ 6.360,94$ & $\$ 19.814,41$ & $10,71 \%$ \\
\hline $\begin{array}{l}\text { recargo aguardiente } \\
\text { extranjera }\end{array}$ & $\$ 1.131,50$ & $\$ 2.669,50$ & $\$ 1.764,50$ & $\$ 1.611,12$ & $\$ 7.176,62$ & $3,88 \%$ \\
\hline $\begin{array}{l}\text { peaje para } \\
\text { composición de } \\
\text { caminos }\end{array}$ & $\$ 521,59$ & $\$ 754,40$ & $\$ 467,40$ & $\$ 818,68$ & $\$ 2.562,07$ & $1,38 \%$ \\
\hline papel sellado & $\$ 150,31$ & $\$ 540,81$ & $\$ 310,00$ & $\$ 260,00$ & $\$ 1.261,12$ & $0,68 \%$ \\
\hline impuesto de tránsito & $\$ 411,00$ & $\$ 219,65$ & $\$ 189,94$ & $\$ 6,96$ & $\$ 827,55$ & $0,45 \%$ \\
\hline trasbordo & $\$ 37,30$ & $\$ 319,90$ & $\$ 44,14$ & $\mathrm{x}$ & $\$ 401,34$ & $0,22 \%$ \\
\hline despacho de buques & $\$ 48,00$ & $\$ 78,00$ & $\$ 69,00$ & $\$ 189,00$ & $\$ 384,00$ & $0,21 \%$ \\
\hline extracción añil & $\$ 414,00$ & $\mathrm{x}$ & $\mathrm{x}$ & $\mathrm{x}$ & $\$ 414,00$ & $0,22 \%$ \\
\hline extracción oro y plata & $\mathrm{x}$ & $\$ 72,96$ & $\mathrm{x}$ & $\mathrm{x}$ & $\$ 72,96$ & $0,04 \%$ \\
\hline
\end{tabular}

Fuente: elaboración propia a partir de Gaceta..., San Salvador, 22 octubre 1847; 1 noviembre $1850 ; 24$ octubre 1851; 28 octubre 1853.

En 1842 , se cobraba un 20\% por importación de productos entre los Estados centroamericanos. Eso significaba que un producto que hubiera atravesado dos o tres estados hasta su destino final había acumulado hasta un 40 o $60 \%$ de alcabala. No obstante, el cobro de los impuestos no se traducía en un aumento de liquidez en la hacienda porque se aceptaba el pago en bonos del Estado hasta un máximo de la mitad del monto ${ }^{35}$. En la década de 1850, los efectos introducidos por Honduras tenían un gravamen de un $14 \%$. Por Guatemala tenían un 28\%. Toda importación marítima tenía un $24 \%$ que se pagaba por terceras partes en dinero, bonos y órdenes.

Siguiendo en el ámbito de las exportaciones, se cargó la extracción de añil con tres pesos y dos reales por cada zurrón de añil de 150 libras (los tres pesos se podían pagar en vales y bonos y los dos reales en moneda efectiva). Según la ley, los dos real eran destinados a la Universidad ${ }^{36}$. A cada tercio de 150 libras se le asignaba una guía de añil que tenía un valor de un real y servía para transitar con el añil por el Estado. Los arrieros entregaban las guías a los administradores de aduanas marítimas cuando la extracción se hacía por los puertos del Sur, y a los guardas de Jocoro o el Sauce, Rodeo, Metapam, Santa Ana, Ahuachapán y Chalatenango cuando se extraían por las fronteras del Norte ${ }^{37}$. El uso de las guías fue un intento de recortar el contrabando y la corrupción que todavía existía, especialmente a nivel local y aduanal. La forma más

\footnotetext{
35 Decreto del gobierno, 2-VI-1846, Libro 8, Título 4, en MENÉNDEZ, 1956, p. 139; NAYLOR, 1988 , p. 54.

36 Decreto legislativo, 25-II-1852, Libro 8, Título 3, Ibídem, p. 132.

37 Reglamento sobre uso y administración de guías para el añil, 11-IV-1855, Libro 8, Título 4, MENÉNDEZ, 1956, p. 135.
} 
elegante era la confabulación del importador y el empleado de aduanas para pagar sólo una parte de los impuestos y embolsarse el último una parte del dinero. A partir de 1843 se obligó a llevar guía para todas las mercancías que se transportaban porque hubo muchos comerciantes que llevaban mercancías destinadas a distintos lugares y transitaban sin guía por haberla entregado en el primer punto, lo cual era considerado contrabando ${ }^{38}$. Todas las guías recolectadas se remitían a la Contaduría Mayor al final del año económico, aunque no hay evidencia de esto por el momento y lo registrado en la aduana de La Unión es ínfimo; igual que el impuesto de un $2 \%$ a la extracción de oro y plata ${ }^{39}$. Las brozas ${ }^{40}$ minerales tenían que pagar cuatro reales por quintal en concepto de exportación.

En orden de importancia, el tercer lugar fue para el cargo al bodegaje y almacenaje. Como medida de control, todos los productos introducidos por tierra o mar debían entrar en los almacenes de aduanas para proceder al recuento y pago. Hubo algunas excepciones, pues a partir de 1841 los productos de los otros Estados centroamericanos quedaron eximidos de ello ${ }^{41}$. Este impuesto, junto al de aguada y al de peaje de caminos, estuvo destinado a la mejora de los puertos. El impuesto por tonelaje consistía en ocho pesos por buque extranjero de menos de 50 toneladas, 12 pesos los de menos de 100 toneladas, y 16 pesos los de más de $100^{42}$. Estuvieron exentos aquellos buques en tránsito, para hacer aguada o refugiados por tempestad. El derecho de tránsito consistía en el pago de dos reales por cabeza de ganado que atravesara el territorio del Estado. El tránsito de productos se gravó con un 2\% porque en el punto de consumo se pagaría el resto de derechos. Existió un impuesto a la sal extranjera a razón de ocho reales por quintal introducido ${ }^{43}$ y por el trasbordo de mercancías en puerto un $2 \%{ }^{44}$. Los impuestos sobre los licores y el aguardiente se componían de dos reales más los derechos aplicados por leyes anteriores ${ }^{45}$. El papel sellado fue un estanco de origen colonial, cuya venta era monopolizada por el Estado como mecanismo para oficializar y formalizar toda transacción ante el Estado o personas y evitar versiones fraudulentas de documentos oficiales ${ }^{46}$.

\subsubsection{La asignación de los gastos}

La distribución de los gastos de los fondos aduanales de La Unión puede dividirse en siete apartados (Cuadro 4). El mayor monto, un 59,17\% del total se destinó a cubrir los compromisos de la deuda pública, concretamente a pagar los bonos del Estado $(36,99 \%)$. A esta cantidad se le podría añadir las destinadas a los Rembolsos por empréstitos voluntarios y forzosos que también formarían parte de la deuda estatal.

\footnotetext{
38 Decreto del gobierno, 20-VI-1843, Libro 8, Título 4. Ibídem, p. 137.

39 Decreto del gobierno, 28-IV-1843, Libro 8, Título 2. Ibídem, p. 129.

40 Mineral sin beneficiar, sin pulir.

41 Decreto legislativo, 18-II-1841, Libro 8, Título 2, Ibídem, p. 116.

42 Decreto legislativo, 19-II-1852, Libro 8, Título 5, Ibídem, p. 155.

43 Decreto legislativo, 11-VII-1842, Libro 8, Título 4, Ibídem, p. 137.

44 Acuerdo del gobierno, 12-V-1843, Libro 8, Título 5, Ibídem, p. 152.

45 Decreto legislativo de 27-IX-1842, Libro 8, Título 4, Ibídem, p. 137.

46 Walter - Ramírez, 2008, p. 150.
} 
Seguido de un $19,18 \%$ del total que se remitía directamente a las arcas de la tesorería general o se empleaba en gastos relacionados con sostenimiento del gobierno ejecutivo. Llama la atención el concepto de "pagos de orden superior" que se supone que servía para financiar al ejecutivo en momentos de necesidad. A continuación sobresale el 7,15\% de gasto militar, sobre todo para suplir a la guarnición portuaria de todos sus efectos. Finalmente destaca las sumas destinadas a la construcción de infraestructuras distribuidas en un 0,50\% remitido a la Junta Itineraria de San Miguel y un $6,14 \%$ para el pago de contratas.

Esta distribución de gastos se explica por el contexto político-económico de constantes batallas e incursiones militares y la fuerte dependencia financiera del exterior. Los datos, aunque solo de una parcela de la Hacienda pública, revelan la hoja de ruta de los grupos gobernantes puesto que los compromisos con sus acreedores fueron la máxima preocupación. El aspecto de la deuda interna, que por falta de espacio solo podemos enunciar, requiere un estudio en profundidad para poder valorar el destino final de esos recursos financieros que se conseguían por fuerza o por voluntad y que alimentaron los proyectos caudillistas que se sucedieron en las décadas centrales del siglo.

Cuadro 4. Gastos efectuados con fondos aduanales de La Unión, 1847, 1850, 1851, 1853

\begin{tabular}{|c|c|c|c|c|c|c|c|c|c|}
\hline & & 1847 & 1850 & 1851 & 1853 & TOTAL & $\%$ & TOTAL & $\%$ \\
\hline \multirow{4}{*}{ 赵 } & gastos militares & & $\$ 1.099,00$ & $\$ 137,21$ & & $\$ 1.236,21$ & $0,53 \%$ & $\$ 16.627,90$ & 7,15 \\
\hline & sueldos militares & $\$ 728,75$ & $\$ 1.000,25$ & $\$ 1.304,50$ & $\$ 980,00$ & $\$ 4.013,50$ & $1,73 \%$ & & \\
\hline & haberes de la fuerza & $\$ 1.170,24$ & $\$ 2.358,56$ & $\$ 1.898,96$ & $\$ 5.874,87$ & $\$ 11.302,63$ & $4,86 \%$ & & \\
\hline & pensión inválidos & & & & $\$ 75,56$ & $\$ 75,56$ & $0,03 \%$ & & \\
\hline \multirow{2}{*}{ 䃾 } & $\begin{array}{l}\text { créditos } \\
\text { reconocidos }\end{array}$ & $\$ 30.662,34$ & $\$ 16.102,00$ & $\$ 4.809,30$ & & $\$ 51.573,64$ & $22,18 \%$ & $\$ 137.588,79$ & 59,17 \\
\hline & $\begin{array}{l}\text { amortización bonos } \\
1^{\mathrm{a}}, 2^{\mathrm{a}}, 3^{\mathrm{a}}\end{array}$ & $\$ 144,06$ & $\$ 30.938,75$ & $\$ 17.977,09$ & $\$ 36.955,25$ & $\$ 86.015,15$ & $36,99 \%$ & & \\
\hline \multirow{4}{*}{ 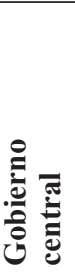 } & $\begin{array}{l}\text { enterados tesorería } \\
\text { general }\end{array}$ & $\$ 1.682,00$ & $\$ 1.000,00$ & $\$ 3.155,25$ & $\$ 21.174,59$ & $\$ 27.011,84$ & $11,62 \%$ & $\$ 44.600,19$ & 19,18 \\
\hline & $\begin{array}{l}\text { gastos } \\
\text { extraordinarios } \\
\text { Gobierno }\end{array}$ & & $\$ 1.769,12$ & $\$ 541,93$ & $\$ 1.411,50$ & $\$ 3.722,55$ & $1,60 \%$ & & \\
\hline & viáticos y dietas & & & $\$ 700,00$ & $\$ 1.050,00$ & $\$ 1.750,00$ & $0,75 \%$ & & \\
\hline & $\begin{array}{l}\text { pagos de orden } \\
\text { superior }\end{array}$ & $\$ 10.897,55$ & & & $\$ 1.218,25$ & $\$ 12.115,80$ & $5,21 \%$ & & \\
\hline \multirow{2}{*}{ 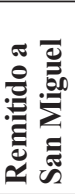 } & \begin{tabular}{|l} 
tesorería j. \\
itineraria de S. \\
Miguel \\
\end{tabular} & $\$ 521,62$ & & & $\$ 630,87$ & $\$ 1.152,49$ & $0,50 \%$ & $\$ 1.548,74$ & 0,67 \\
\hline & $\begin{array}{l}\text { remisión recargo } \\
\text { aguardiente }\end{array}$ & $\$ 7,50$ & & & $\$ 388,75$ & $\$ 396,25$ & $0,17 \%$ & & \\
\hline
\end{tabular}




\begin{tabular}{|c|c|c|c|c|c|c|c|c|c|}
\hline \multirow{4}{*}{ 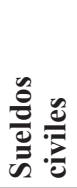 } & empleados aduanas & $\$ 3.064,30$ & $\$ 2.856,70$ & $\$ 5.390,40$ & $\$ 2.453,91$ & $\$ 13.765,31$ & $5,92 \%$ & $\$ 14.782,31$ & 6,36 \\
\hline & CSJ & & & & $\$ 363,56$ & $\$ 363,56$ & $0,16 \%$ & & \\
\hline & contaduría mayor & & & & $\$ 419,31$ & $\$ 419,31$ & $0,18 \%$ & & \\
\hline & gobernadores & & & & $\$ 234,13$ & $\$ 234,13$ & $0,10 \%$ & & \\
\hline \multirow{4}{*}{ 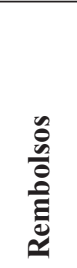 } & $\begin{array}{l}\text { sustracción violenta } \\
\text { de plata }\end{array}$ & & $\$ 474,00$ & & & $\$ 474,00$ & $0,20 \%$ & $\$ 16.252,47$ & 6,99 \\
\hline & $\begin{array}{l}\text { devolución } \\
\text { préstamos } \\
\text { voluntarios } \\
\end{array}$ & & & $\$ 500,00$ & $\$ 1.000,00$ & $\$ 1.500,00$ & $0,65 \%$ & & \\
\hline & pago por contratas & $\$ 3.823,22$ & & $\$ 730,00$ & $\$ 9.715,25$ & $\$ 14.268,47$ & $6,14 \%$ & & \\
\hline & $\begin{array}{l}\text { equívocos } \\
\text { deshechos }\end{array}$ & & $\$ 10,00$ & & & $\$ 10,00$ & $0,00 \%$ & & \\
\hline \multirow{3}{*}{ 气 } & aduana & & $\$ 21,75$ & $\$ 25,31$ & $\$ 30,00$ & $\$ 77,06$ & $0,03 \%$ & $\$ 1.124,81$ & 0,48 \\
\hline & comandancia & & $\$ 18,00$ & $\$ 18,00$ & $\$ 18,00$ & $\$ 54,00$ & $0,02 \%$ & & \\
\hline & $\begin{array}{l}\text { extraordinarios } \\
\text { aduana }\end{array}$ & $\$ 819,20$ & $\$ 40,62$ & $\$ 16,68$ & $\$ 117,25$ & $\$ 993,75$ & $0,43 \%$ & & \\
\hline
\end{tabular}

Fuente: elaboración propia a partir de Gaceta..., San Salvador, 22 octubre 1847; 1 noviembre 1850; 24 octubre 1851; 21 enero 1853; 28 octubre 1853.

\subsection{La huella de las rentas de San Miguel en la economía salvadoreña}

El flujo comercial en Oriente significó una circulación de recursos fiscales en la aduana de La Unión que permitió responder a los compromisos estatales. A continuación se hace el mismo ejercicio con las rentas de San Miguel recaudadas fundamentalmente por la actividad comercial. No obstante, estudiar esta región exige valorar la existencia del sector económico campesino que participó del dinamismo económico expuesto en estas líneas, pero del que no hay evidencias escritas. Bulmer-Thomas reconoció la deficiencia que supone el desconocimiento de la economía no exportadora por la falta de registro y estadística de la producción agrícola para el consumo interno, la producción artesanal y algunos servicios como la navegación costera. Si bien fue poco productiva e ineficiente, sus niveles fueron más altos que las exportaciones ${ }^{47}$.

Las ferias, a las cuales ya se ha hecho referencia, fueron también clave para dinamizar el comercio y la economía de la región. En el ámbito local tuvieron un papel fundamental porque su realización dependía de las municipalidades. El concejo municipal, con parte de los fondos locales, iniciaba los preparativos en los primeros días del mes de noviembre cuando se subastaban los chinamos, que solían tener un perímetro de tres a seis varas, y su ubicación en la ciudad ${ }^{48}$. Además del derecho de plaza por el uso de un chinamo $^{49}$ (en proporción a las ventas y al terreno ocupado sin exceder los dos reales ${ }^{50}$ ), la afluencia de gente a la feria creó otras fuentes de ingresos para la hacienda local como alquileres de casa, manutención de los visitantes, zacate para los animales, etc.

47 Bulmer-Thomas, 2003, p. 57.

48 Avisos, en Gaceta..., 18-X-1855.

49 Tenderete improvisado.

50 Decreto legislativo, 16-III-1849, Libro 8, Título 2, MEnÉndez, 1956, p. 119. 


\subsubsection{Los ingresos departamentales}

En el ámbito de las entradas fiscales regionales un $47,75 \%$ de los fondos departamentales procedía del ramo del aguardiente (Cuadro 5). Sin embargo los niveles de actividad económica visibles con el indicador de la alcabala, no fueron desdeñables. Casi un $23 \%$ de los ingresos fueron a razón del pago de la alcabala marítima y la interior, ésta última consistía en un $4 \%$ que se hacía por cualquier transacción comercial, salvo los productos de primera necesidad producidos en el país que no estaban gravados. El ramo del tajo por el destace de animales y los derechos de extracción de añil componían un segundo sector en orden de importancia en los ingresos departamentales.

Se entiende que los conceptos de la alcabala marítima, los derechos de extracción, los recargos al aguardiente, el papel sellado y el tránsito que aparecían en las cuentas departamentales absorbían los montos equivalentes que, como se ha visto antes, se recaudaban también en la aduana de La Unión. Por lo tanto, los datos fiscales departamentales dan una visión general y proporcionada de la dinámica económica regional.

Cuadro 5. Tipo de impuestos y cantidades recaudadas en la administración de rentas de San Miguel, 1851-1855 (en pesos)

\begin{tabular}{|l|r|r|r|r|r|r|}
\hline Impuestos & \multicolumn{1}{|c|}{$\mathbf{1 8 5 1}$} & \multicolumn{1}{c|}{$\mathbf{1 8 5 3}$} & \multicolumn{1}{c|}{$\mathbf{1 8 5 4}$} & \multicolumn{1}{c|}{$\mathbf{1 8 5 5}$} & \multicolumn{1}{c|}{ TOTAL } & \multicolumn{1}{c|}{$\%$} \\
\hline alcabala marítima e interior & $9.476,24$ & $12.760,22$ & $13.413,77$ & $11.161,30$ & $46.811,53$ & $22,93 \%$ \\
\hline impuesto extracción añil & 16,00 & $6.058,50$ & $2.451,31$ & $1.865,00$ & $10.390,81$ & $5,09 \%$ \\
\hline id extracción plata & & 504,87 & 113,68 & 232,46 & 851,01 & $0,42 \%$ \\
\hline ramo aguardiente & $7.674,43$ & $27.036,37$ & $29.582,39$ & $33.188,00$ & $97.481,19$ & $47,75 \%$ \\
\hline papel sellado & 883,25 & $2.041,40$ & $2.095,25$ & $2.116,21$ & $7.136,11$ & $3,50 \%$ \\
\hline reposición papel sellado & 13,25 & 11,50 & & 377,59 & 402,34 & $0,20 \%$ \\
\hline ramo tabaco & 916,37 & $3.210,00$ & & & $4.126,37$ & $2,02 \%$ \\
\hline ramo tajo & $1.457,75$ & $3.639,25$ & $4.036,25$ & $4.194,75$ & $13.328,00$ & $6,53 \%$ \\
\hline asiento de gallos & 64,00 & 124,00 & 430,00 & 638,50 & $1.256,50$ & $0,62 \%$ \\
\hline donativos & 72,00 & & 114,00 & 75,00 & 261,00 & $0,13 \%$ \\
\hline empréstitos & $8.708,00$ & & & & $8.708,00$ & $4,27 \%$ \\
\hline depósitos & 213,31 & $4.126,62$ & 17,50 & 19,00 & $4.376,43$ & $2,14 \%$ \\
\hline devolución por tesorería & 11,00 & & & & 11,00 & $0,01 \%$ \\
\hline comisos & & 213,60 & 26,25 & 69,55 & 309,4 & $0,15 \%$ \\
\hline tránsito ganado & & $2.399,75$ & $2.059,50$ & $3.552,75$ & 8012 & $3,92 \%$ \\
\hline Manda forzosa y 1/2 \% & & 400,00 & 6,00 & 282,00 & 688 & $0,34 \%$ \\
\hline TOTAL ingresos anuales & $29.545,70$ & $62.374,20$ & $54.433,60$ & $58.132,65$ & $204.149,69$ & $100,00 \%$ \\
\hline
\end{tabular}

Fuente: elaboración propia a partir de Gaceta... San Salvador, 14 noviembre 1851; 21 octubre $1853 ; 2$ noviembre $1854 ; 1$ noviembre 1855 . *Incluye sólo de marzo a septiembre. 


\subsubsection{La distribución de fondos departamentales}

La organización de gastos hecha a partir de los recursos fiscales de la administración de rentas de San Miguel siguió la misma lógica que en la aduana de La Unión (Cuadro 6). El pago de la deuda pública estatal fue la primera obligación a cumplir $(43,46 \%)$. El segundo destino de los recursos fue el gasto militar, sobretodo en la inversión en el haber de la fuerza del departamento de San Miguel (11,94\%). Un gasto justificado por la posición del departamento en el extremo oriental de la República y la presencia de un punto estratégico para el Estado como el puerto de La Unión, que fue motivo de ataques y ocupaciones frecuentes por parte de los otros Estados del istmo. El tercer dispendio fuerte fueron las sumas que se destinaban al mantenimiento del gobierno central.

Cuadro 6. Gastos efectuados con los fondos de la Administración de Rentas de San Miguel, $1851,1853-1855$ (en pesos)

\begin{tabular}{|c|c|c|c|c|c|c|c|c|c|}
\hline & Egresos & 1851 & 1853 & 1854 & 1855 & TOTAL & $\%$ & TOTAL & $\%$ \\
\hline \multirow{4}{*}{ 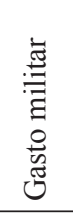 } & haberes de la fuerza & $2.011,69$ & $8.306,31$ & $5.563,90$ & $8.219,65$ & $24.101,55$ & $11,94 \%$ & \multirow{4}{*}{$36.955,26$} & \multirow{4}{*}{$18,31 \%$} \\
\hline & sueldos jefes y oficiales & $1.569,24$ & $3.775,20$ & $3.395,44$ & $1.878,88$ & $10.618,76$ & $5,26 \%$ & & \\
\hline & gastos militares & 654,62 & 65,00 & 198,62 & 867,00 & $1.785,24$ & $0,88 \%$ & & \\
\hline & $\begin{array}{l}\text { pensión inválidos y } \\
\text { montepío militar }\end{array}$ & 284,50 & 119,90 & & 45,31 & 449,71 & $0,22 \%$ & & \\
\hline \multirow{3}{*}{ 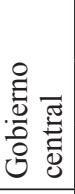 } & $\begin{array}{l}\text { remitidos a tesorería } \\
\text { general }\end{array}$ & $10.129,00$ & $2.399,00$ & $6.326,00$ & $6.098,00$ & $24.952,00$ & $12,37 \%$ & \multirow{3}{*}{$27.489,45$} & \multirow{3}{*}{$13,62 \%$} \\
\hline & \begin{tabular}{|l} 
gastos extraordinarios \\
Supremo Gobierno
\end{tabular} & & & & $1.381,00$ & $1.381,00$ & $0,68 \%$ & & \\
\hline & $\begin{array}{l}\text { presupuesto SCJ y } \\
\text { dependientes }\end{array}$ & 157,60 & 998,85 & & & $1.156,45$ & $0,57 \%$ & & \\
\hline 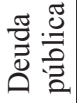 & $\begin{array}{l}\text { amortización bonos } \\
\text { y vales }\end{array}$ & $7.437,97$ & $33.343,32$ & $24.212,30$ & $22.693,72$ & $87.687,31$ & $43,46 \%$ & $87.687,31$ & $43,46 \%$ \\
\hline \multirow{3}{*}{ 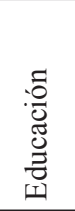 } & $\begin{array}{l}\text { remitidos a Tesorería } \\
\text { gral instrucción pública }\end{array}$ & 213,31 & $3.004,50$ & $2.245,00$ & $3.912,06$ & $9.374,87$ & $4,65 \%$ & \multirow{3}{*}{$21.758,62$} & \multirow{3}{*}{$10,78 \%$} \\
\hline & $\begin{array}{l}\text { remitidos a Teso. } \\
\text { instrucción pública } \\
\text { dpto. }\end{array}$ & & 970,00 & $1.398,00$ & 606,00 & $2.974,00$ & $1,47 \%$ & & \\
\hline & sueldo preceptores & $1.179,25$ & $2.275,00$ & $2.431,25$ & $3.524,25$ & $9.409,75$ & $4,66 \%$ & & \\
\hline \multirow{5}{*}{ 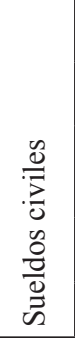 } & $\begin{array}{l}\text { sueldos jueces } 1^{\text {a }} \text { inst } \\
\text { y asesor }\end{array}$ & 824,81 & 957,00 & $5.247,40$ & $4.919,96$ & $11.949,17$ & $5,92 \%$ & \multirow{5}{*}{$20.716,27$} & \multirow{5}{*}{$10,27 \%$} \\
\hline & $\begin{array}{l}\text { sueldo gobernador y } \\
\text { dependientes }\end{array}$ & 913,93 & 913,30 & & & $1.827,23$ & $0,91 \%$ & & \\
\hline & $\begin{array}{l}\text { honorario } \\
\text { administrador y } \\
\text { comisario }\end{array}$ & 611,99 & $1.435,90$ & $1.468,10$ & $1.591,57$ & $5.107,56$ & $2,53 \%$ & & \\
\hline & $\begin{array}{l}\text { viáticos y dietas DD, } \\
\text { SS y dependientes } \\
\end{array}$ & 328,77 & $1.423,54$ & & & $1.752,31$ & $0,87 \%$ & & \\
\hline & policía & & 20,00 & & 60,00 & 80,00 & $0,04 \%$ & & \\
\hline
\end{tabular}




\begin{tabular}{|c|c|c|c|c|c|c|c|c|c|}
\hline & pagos por contratas & & & & 544,04 & 544,04 & $0,27 \%$ & \multirow{5}{*}{$3.874,15$} & \multirow{5}{*}{$1,92 \%$} \\
\hline \multirow{4}{*}{ 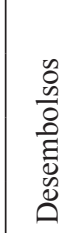 } & $\begin{array}{l}\text { pagos a cosecheros } \\
\text { tabaco }\end{array}$ & 290,00 & & & & 290,00 & $0,14 \%$ & & \\
\hline & $\begin{array}{l}\text { pagos administración } \\
\text { de La Unión }\end{array}$ & 100,00 & & & & 100,00 & $0,05 \%$ & & \\
\hline & $\begin{array}{l}\text { devolución por } \\
\text { préstamo }\end{array}$ & 991,68 & 304,50 & 775,43 & 36,00 & $2.107,61$ & $1,04 \%$ & & \\
\hline & resguardo & 300,00 & 532,50 & & & 832,50 & $0,41 \%$ & & \\
\hline 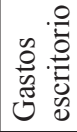 & $\begin{array}{l}\text { gastos ordinarios } \\
\text { escritorio }\end{array}$ & 76,50 & 136,00 & 46,25 & 46,87 & 305,62 & $0,15 \%$ & 305,62 & $0,15 \%$ \\
\hline \multirow{4}{*}{ 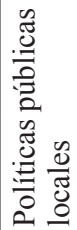 } & $\begin{array}{l}\text { enterados Tesorería } \\
\text { hospital }\end{array}$ & 85,00 & & & & 85,00 & $0,04 \%$ & \multirow{4}{*}{$3.000,83$} & \multirow{4}{*}{$1,49 \%$} \\
\hline & id Tesorería alumbrado & 100,00 & & & & 100,00 & $0,05 \%$ & & \\
\hline & $\begin{array}{l}\text { gastos civiles } \\
\text { ordinarios }\end{array}$ & & & 170,00 & 209,50 & 379,50 & $0,19 \%$ & & \\
\hline & gastos extraordinarios & 927,71 & 922,62 & 586,00 & & $2.436,33$ & $1,21 \%$ & & \\
\hline
\end{tabular}

Fuente: elaboración propia a partir de Gaceta... San Salvador, 14 noviembre 1851; 21 octubre 1853; 2 noviembre 1854; 1 noviembre 1855 . *Incluye sólo de marzo a septiembre.

Finalmente un $10,78 \%$ se destinaba a la educación organizado en tres conceptos relacionados: el sueldo de los preceptores, el monto remitido a la tesorería departamental de instrucción pública y el destinado a la caja de la tesorería general de Instrucción pública. Ésta última fue proporcionalmente la suma más importante $(4,65 \%)$, si se tiene en cuenta la continuidad de los datos.

Valorando la coyuntura de guerra constante, el porcentaje de recursos destinados a gastos militares nos parece muy escaso si lo comparamos con los fondos destinados al pago de la deuda pública, tanto en la administración de rentas de San Miguel como en la aduana de La Unión. Aún no hay estudios que lo confirmen, pero posiblemente gran parte de esta deuda englobaba empréstitos realizados en vistas a financiar la guerra.

\section{A MODO DE CONCLUSIÓN}

Tras la revisión de los indicadores se puede constatar que a partir de 1824 el puerto de La Unión atrajo gran parte del movimiento marítimo de las costas salvadoreñas, concentrándose la entrada de barcos en los meses de la feria de San Miguel, noviembre y mayo. El principal producto de exportación fue el añil aunque se asiste a un progresivo declive por el contexto político del istmo y la caída de los precios por la competencia de los tintes de la India. No obstante, ejerció su predominio hasta la década de 1870 cuando el café lo superó definitivamente en las exportaciones. El flujo comercial que llegaba por La Unión canalizó recursos y un mercado hacia el interior del departamento. La ciudad de San Miguel fue el centro neurálgico de ese comercio que se llevaba a cabo principalmente durante las ferias, acontecimiento logísticamente dependiente del consejo municipal que fue un espacio de contacto entre el mercado local y el comercio 
internacional. Agentes salvadoreños y extranjeros, vendedores del departamento, nicaragüenses, hondureños y guatemaltecos formaron parte de una jerarquía financieracomercial que actuó en la zona oriental y que dinamizó la economía de la región.

La importancia económica regional quedó reflejada en la fiscalidad y confirió un papel clave al oriente salvadoreño. En la débil estructura fiscal del Estado la aduana del puerto de La Unión y la administración departamental de rentas de San Miguel fueron una fuente importante de recursos tanto para la región como para el Estado. La mayor parte de estos recursos se destinaron a obligaciones estatales como los gastos militares y el pago de la deuda interna contraída con comerciantes y prestamistas para hacer la guerra.

En conclusión y en relación a la hipótesis planteada al inicio, la región oriental de El Salvador tuvo una importante función en el desarrollo económico del país y en la temprana formación estatal. La continuidad en las investigaciones debería seguir tres líneas concretas. Primero seria conveniente valorar la cuestión del ramo aguardiente que como se ha podido comprobar también tuvo un papel importante en la fiscalidad oriental, sin embargo la poca disponibilidad de fuentes ha impedido integrarlo y profundizar más en el análisis. En segundo lugar convendría dedicar esfuerzos en hacer una comparación de los mismos indicadores en otras regiones del estado como el occidente o la zona central para valorar su posición en la evolución económica general. En tercero lugar, valdría la pena enfocarse en estudios específicos de personajes como Joaquín Mathé, Florentin Souza o Yanuario Blanco porque al ser comerciantes destacados, probablemente sus negocios y redes sociales encierren muchas respuestas en torno al comercio y las relaciones económicas en la región oriental.

Ésta ha sido una aproximación, sin ánimo de exhaustividad, a la realidad económica del Oriente salvadoreño a partir del comercio exterior y la fiscalidad regional en el marco de la dinámica económica nacional. No se busca agotar el tema sino abrir la puerta a nuevas discusiones historiográficas, inexistentes hasta el momento, sobre la formación estatal salvadoreña desde la perspectiva regional.

\section{REFERENCIAS BIBLIOGRÁFICAS}

Acosta, Antonio

2006 "Articulación territorial y fractura social. Una aproximación desde la fiscalidad en El Salvador a fines del XIX". En GARCía Jordán (ed.) Homogeneidad, diferencia y exclusión en América. Barcelona. Publicaciones i Ediciones Universitat de Barcelona.

2007a "Hacienda y finanzas de un Estado oligárquico. El Salvador, 1874-1890". En GARCíA JoRDÁn (ed.) Estado, región y poder local en América latina, siglos XIX-XX. Barcelona. Taller de Estudios e Investigaciones AndinoAmazónicos - Publicacions i Edicions Universitat de Barcelona, pp. 17-79.

2007b "Municipio, Estado y crisis económicas. El Salvador, 1870-1880. Una contribución al análisis desde las haciendas municipales". Revista de Indias. Madrid, vol LXVII, n²40, pp. 367-402. 
2008 "Tierra y café en El Salvador en la primera expansión del cultivo: 18601890. Algunas precisiones". En Dalla Corte (ed.) Poder local, poder global en América Latina. Barcelona. Publicaciones i Edicions Universitat de Barcelona.

AvENDAÑo, Xiomara

2006 "Sin sujeción a Dios, la Iglesia o al Rey: aldeas y pueblos en San Miguel de la Frontera a finales del periodo colonial". Ponencia presentada en VIII Congreso Centroamericano de Historia. Antigua (Guatemala), 10-14 julio. (Inédito).

Belot, Gustave

1865 La Republique du Salvador. Paris. Chez Dentú editeur.

BRownING, David

1974 El Salvador, la tierra y el hombre. San Salvador. Dirección de Publicaciones e Impresos.

Bulmer-Thomas, Víctor

2003 La historia económica de América Latina desde la Independencia. México. Fondo de Cultura Económica.

CAMPos, Oscar

2006 Estado, economía y redes de poder en el Oriente salvadoreño, 1876-1915. San Salvador. Facultad de Ciencias Sociales, Universidad Tecnológica de El Salvador.

2010 "Puerto El Triunfo: la disputa de intereses regionales en el oriente salvadoreño, 1894-1918". Boletín AFEH, no 47, disponible en: http://afehchistoria-centroamericana.org/index.php?action=fi_aff\&id=2546.

Cardoso, Ciro F. - Pérez-Brignoli, Héctor

1977 Centroamérica y la economía Occidental (1520-1930). San José. Ediciones Universidad de Costa Rica.

Chamberlain, Robert S.

1947 "The Early Years of San Miguel de la Frontera". En The Hispanic American Historical Review. Durham, vol. 27, nº, pp. 623-646.

ColindRes, Eduardo

1977 Fundamentos económicos de la burguesía salvadoreña. San Salvador. UCA Editores.

DunLOP, Robert

1847 Travels in Central America: being a journal of nearly three years residence in the country: together with a sketch of the history of the republic, and an account of its climate, productions, commerce, etc. London. Longman, Brown, Green, and Longmans.

GACETA

1847-1855 --- del gobierno del Salvador en la América Central. San Salvador.

Gudmundson, Lowell - Lindo-Fuentes, Héctor

1995 Central America 1821-1871. Liberalism before liberal reform. Tucsaloosa - London. The University Alabama Press. 
Lauria Santiago, Aldo

2003 Una república agraria. San Salvador. DPI.

2011 "Holding the City Hostage: Popular Sectors and Elites in San Miguel, El Salvador, 1875". En The Americas. Washington, vol. 68, nº1, (July 2011), pp. 63-95.

LiNDO-FuENTES, Héctor

1993 “Economía y sociedad(1810-1870)”. En Historia General de Centroamérica. Tomo 3. Madrid. Comunidades Europeas - Quinto Centenario - FLACSO.

2002 La economía de El Salvador en el siglo XIX. San Salvador. DPI.

López Bernal, Carlos Gregorio

2007 "Poder central y poder local en la construcción del Estado en El Salvador, 1840-1890”. Tesis para optar al grado de Doctor en Historia. Universidad de Costa Rica. (Inédita).

2008 "Las reformas liberales en El Salvador y sus implicaciones en el poder municipal, 1871-1890”. En Diálogos. Revista electrónica de Historia, $\mathrm{n}^{\mathrm{o}}$ especial, (IX Congreso Centroamericano de Historia).

MENÉNDEZ, Isidro

1956 Recopilación de leyes del Salvador [1855]. San Salvador. Imprenta Nacional.

Menjívar Larín, Rafael

1980 Acumulación originaria y desarrollo del capitalismo en El Salvador. San José. EDUCA.

NAYLOR, Robert A.

1960 "The British Role in Central America Prior to the Clayton-Bulwer Treaty of 1850”. En The Hispanic American Historical Review. Durham, vol. 40, n³, pp. 361-382.

1988 Influencia británica en el comercio centroamericano durante las primeras décadas de la Independencia (1821-1851). Antigua (Guatemala). Centro de Investigaciones Regionales de Mesoamérica.

Payne Iglesias, Elizet

2006 "El puerto y la región: una revisión historiográfica para el estudio del puerto de Truxillo (Honduras)". En Memorias. Revista digital de Historia y arqueología desde el Caribe. Barranquilla, Primer semestre, vol. 3, nº5.

Portillo, Geraldina

2004 "Cafetaleros del departamento de Santa Ana 1882-1898". Ponencia presentada en VII Congreso Centroamericano de Historia, Tegucigalpa. (Inédita).

RoDríguEZ, Mario

1970 Chatfield, cónsul británico en Centro América. Tegucigalpa. Banco Central de Honduras. 
Quesada Monge, Rodrigo

1985 "América Central y Gran Bretaña: la composición del comercio exterior (1851-1915)". En Anuario de Estudios Centroamericanos. San José de Costa Rica, vol. II, n², pp. 77-92.

SCHOONOVER, Thomas

1978 "Central American Commerce and Maritime Activity in the Nineteenth Century: Sources for a Quantitative Approach". En Latin American Research Review. Alburquerque, vol. 13, n², pp. 157-169.

SQUIER, Ephraim

1856 Apuntamientos sobre Honduras y El Salvador. New York. Harper and Brothers.

Solórzano Fonseca, Juan Carlos

1993 "Los años finales de la dominación española (1750-1821)". En Historia General de Centroamérica. Tomo 3. Madrid. Comunidades Europeas Quinto Centenario - FLACSO.

TaRACENA ARriola, Arturo

1993 "Liberalismo y poder político en Centro América". En Historia General de Centroamérica. Tomo 4. Madrid. Comunidades Europeas - Quinto Centenario - FLACSO.

Tempsky, Gustav

1858 A narrative of incidents and personal adventures on a journey in Mexico, Guatemala, and Salvador in the years 1853 to 1855. With observations on the modes of life in those countries. London. Edited by J.S. Bell.

TORRES RIVAs, Edelberto

1980 "Problemas en la formación del Estado Nacional en Centroamérica". Estudios Sociales Centroamericanos. San José de Costa Rica. Mayoagosto, IX, n²6, pp. 155-186.

WaLter, Knut - Ramírez, José Alfredo

2008 "Los estancos en la República del Salvador". En VVAA, Los estancos, las prácticas monopólicas y las rentas del Estado en El Salvador. San Salvador. Superintendencia de Competencia.

Williams, Robert G.

1994 States and Social Evolution. Coffee and the Rise of National Governments in Central America. Chapel Hill - London. University of North Carolina Press. 